JoHnson, F. N. (1984) The History of Lithium Therapy, p. 166, note 62. London: MacMillan.

ScHOU, M. (1963) Normothymotics, "mood-normalizers": Are lithium and the imipramine drugs specific for affective disorders? British Journal of Psychiatry, 109, 803-809.

The Psychiatric Hospital

M. SchоU

2 Skovagerve

DK-8240 Risskov

Denmark

\section{Lithium augmentation}

SIR: Katona et al (BJP, January 1995, 166, 80-86) described a well-designed study of lithium augmentation. I would, nevertheless, like to highlight some weaknesses that the authors did not discuss.

It was admitted that the 'self-generated' group of anti-depressant non-responders were less refractory than patients included in previous studies. I think it is questionable whether many of them were refractory to monotherapy at all. Given that nearly half the patients in Phase II were non-compliant with lithium it seems probable that many apparent nonresponders to lofepramine or fluoxetine in Phase I were actually non-compliant. Preskorn (1989) has appealed for the use of antidepressant plasma concentrations as a criterion of 'true' refractory depression. Such blood tests, although complicating a multi-centre trial, are essential if claims of treatment resistance are to be sustained. Assessing compliance by means of a blood test is far superior to tablet counts.

The assertion that the study sample had 'controlled and documented prior antidepressant treatment' is only true concerning the six week Phase I period. No summary of the lifetime treatment histories of these patients was offered. Thus patients with extensive histories of failed treatment, those most clinicians would perceive as 'refractory', were mixed up with those suffering first episodes of depression.

Finally, it was baldly stated that lithium augmentation is the most important pharmacological strategy in the management of refractory depression. I would argue, following Bridges (1983) and Quitkin (1985), that reviewing compliance with monotherapy by means of an antidepressant plasma concentration, then increasing the dose of that compound where possible, is of equal importance. A multi-centre trial comparing these two strategies is due.

BRmGes, P. K. (1983) “. . . and a small dose of an antidepressant might help." British Journal of Psychiatry, 142, 626-628.
Preskorn, S. H. (1989) The role of tricyclic antidepressant plasma level monitoring. In Treatment of Tricyclic-Resistant Depression. (ed I. L. Extein) American Psychiatric Association: Washington, DC.

QuITKIN, F. M. (1985) The importance of dosage in prescribing antidepressants. British Journal of Psychiatry, 147, 593-597.

\author{
Wellcome Institute for the \\ History of Medicine \\ 183 Euston Road \\ London NWI $2 B E$
}

A.D. HodGKiss

\section{Hypomania induced by gabapentin}

SIR: We report a case of a 49-year-old man with epilepsy and mild learning disabilities who developed symptoms of hypomania on starting gabapentin. The patient had a long-standing history of tonic clonic and partial complex seizures, the latter of which were difficult to control. We added gabapentin $300 \mathrm{mg}$ into his existing regime of carbamazepine and lamotrigine, increasing daily by $300 \mathrm{mg}$ to a maintenance dose of $300 \mathrm{mg}$ t.d.s. Within the next 48 hours his behaviour began to change and he became markedly disinhibited and over familiar towards female staff on the ward, making inappropriate sexual remarks and becoming physically demonstrative. Although he had no flight of ideas, there was evidence of pressure of speech and his sleep pattern was mildly disrupted.

We reduced his gabapentin and his mental state improved without the need for psychotropic medication while maintaining good control of his partial complex seizures. Unfortunately his behaviour became aggressive and unpredictable, culminating in a violent attack on a fellow resident two weeks later. We stopped the gabapentin, and he reverted to his usual self.

The patient did have a past psychiatric history although he had not received a formal diagnosis. In 1988 he had an episode of disinhibited behaviour which in retrospect may have been hypomania although he did not receive any psychotropic treatment at the time.

Gabapentin is a relatively new anti-epileptic drug which is recommended as an adjunctive treatment for patients with refractory partial epilepsy. It is rapidly absorbed, does not bind to protein, is not metabolised, and does not affect serum concentrations of other anticonvulsants. It has been marketed as an ideal anticonvulsant pharmacokinetically. In clinical trials it showed a low relative toxicity. There have been a total of 32 reports received by the Committee of Safety of Medicine of 
psychiatric reactions to gabapentin and only one other report of hypomania.

The drug company advises daily incremental doses until the patient is on a minimum maintenance dose. We suggest that this advice be viewed more cautiously in patients with a past psychiatric history of mood disorder or psychotic disturbance.

C. SHORT

L. COOKE

Stoke Park Hospital

Bristol BS16 1QU

\section{Schizophreniform psychosis after stage hypnosis}

SIR: I wish to report a case of schizophreniform psychosis which developed in a man with no previous psychiatric history after he was the subject of stage hypnosis.

A 25-year-old man attended a performance by a well-known stage hypnotist. He volunteered for hypnosis and 'performed' in front of the audience. The next day his girlfriend described him as 'giggly' at a meeting at work where the possibility of redundancy was being discussed. He complained of headaches. A day later at the theatre he laughed inappropriately throughout the show and over the next three days he developed auditory hallucinations and believed that he was being told what to do. He became very frightened and believed that he was going to die and became quite angry and verbally aggressive towards his girlfriend. He began to emulate his girlfriend's movements and would not let her out of his sight. He had ideas of reference, for example believing that blinking meant something significant to him.

He was admitted informally to an acute psychiatric ward nine days after the stage show. History revealed no evidence of past psychiatric illness. Mental state examination at the time showed evidence of paranoid ideation, ideas of reference and auditory hallucinations in the second person. A diagnosis of an acute schizophrenic episode was made and he was treated with chlorpromazine $100 \mathrm{mg}$ t.d.s. reducing to $150 \mathrm{mg}$ daily over a 3 week period.

He was followed up by a community psychiatric nurse and in the out-patient department where he made a slow recovery, and his medication was tailed off over a period of six months. However, he continued to be very wary about what he watched on television and he described feelings of foreboding on walking past churches. Two months later he had become increasingly perplexed and his chlorpromazine was restarted. Shortly after this he saw a show on television featuring the same stage hypnotist who had hypnotised him and he became quite paranoid, believing that the behaviour of characters in a television soap opera were giving him messages by their behaviour and reading significance into the numbers in the lottery which he felt related in some way to the 'count' after his hypnosis. He was treated with increased doses of chlorpromazine.

Although the psychiatric literature is replete with references to hypnotherapy being used as a treatment for psychosis I could find no record of hypnosis as a precipitant of a psychotic illness. Nevertheless there is evidence that stage hypnosis can lead to a number of subjective negative experiences for participants after the event (Crawford et al, 1992). Just over one-third of respondents in this study reported mild to strong negative experiences including being frightened and confused.

According to the Health \& Safety Executive (Lucas, personal communication) "subjecting sensitive/paranoid individuals to ridicule" can lead to "adverse effects".

In this patient's case it is likely that stage hypnosis was the significant life event which triggered a schizophrenic illness. Clearly there are lessons to be learnt by stage hypnotists about the potentially serious outcome for a very small minority of participants in what is supposed to be a form of entertainment.

\footnotetext{
Crawford, H. J., KItNer-Triolo, M., Clarke, S. W., et al (1992)

Transient positive and negative experiences accompanying stage hypnosis. Journal of Abnormal Psychology, 101, 663-667.

Frischrolz, E. J., Lipman, L. S., Braun, B. G., et al (1992)

Psychopathology, hypnotizability and dissociation. American Journal of Psychiatry, 149, 1521-1525.
}

North Wycombe C.M.H.T.

D. S. Allen

\section{Cedar Avenue}

Hazlemere

High Wycombe

Bucks. HP15 7DW

\section{Nietzsche, Freud and eternal recurrence of the repressed ...}

SIR: I read Chapman \& Chapman-Santana's paper on the influence of Nietzsche on Freud's ideas with interest (BJP, February 1995, 166, 251-253). I was, however, rather disappointed that the authors mention only fleetingly the pivotal achievement of Nietzschean thought - the eternal recurrence - and make no connection between this and the cardinal Freudian idea of 'repetition compulsion'. In Beyond Good and Evil Nietzsche translates Zarathustra's 